\title{
Another possible food-borne outbreak of hepatitis A in the Netherlands indicated by two closely related molecular sequences, July to October 2011
}

N Fournet (nelly.fournet@rivm.nl)1,2, D Baas³, W van Pelt ${ }^{1}$, C Swaan ${ }^{4}$, H J Ober ${ }^{5}$, L Isken ${ }^{4}$, J Cremer ${ }^{3}$, I Friesema ${ }^{1}$, H Vennema $^{3}$, I Boxman ${ }^{5}$, M Koopmans $^{3}$, L Verhoef 3

1. Epidemiology and Surveillance Unit, Center for Infectious Diseases Control, National Institute for Public Health and the Environment (Rijksinstituut voor Volksgezondheid en Milieu, RIVM), Bilthoven, the Netherlands

2. European Programme for Intervention Epidemiology Training (EPIET), European Centre for Disease Prevention and Control (ECDC), Stockholm, Sweden

3. Laboratory for Infectious Diseases and Screening, Centre for Infectious Disease Control, National Institute for Public Health and the Environment (Rijksinstituut voor Volksgezondheid en Milieu, RIVM), Bilthoven, the Netherlands

4. Preparedness and Response Unit, Centre for Infectious Disease Control, National Institute for Public Health and the Environment (Rijksinstituut voor Volksgezondheid en Milieu, RIVM), Bilthoven, the Netherlands

5. Food and Consumer Product Safety Authority (Nederlandse Voedsel en Waren Autoriteit), Utrecht, the Netherlands

Fournet N, Baas D, van Pelt W, Swaan C, Ober HJ, Isken L, Cremer J, Friesema I, Vennema H, Boxman I, Koopmans M, Verhoef L. Another possible food-borne outbreak of hepatitis A in the Netherlands indicated by two closely related molecular sequences, July to October 2011.

Euro Surveill. 2012;17(6):pii=20079. Available online: http://www.eurosurveillance.org/ViewArticle.aspx?Articleld=20079

Article published on 9 February 2012

In November 2011, a cluster of initially five cases of hepatitis A infection with closely related strains was identified in the Netherlands. England reported possibly related cases. Strains with identical sequences had been involved in previous outbreaks linked to semi-dried tomatoes. Investigation of the Dutch cluster suggested a link with ready-to-eat salads including those containing semi-dried tomatoes. Despite traceback, a source was not identified. Vigilance is needed, and rapid sharing of data may help source-tracing.

In November 2011, a cluster of five cases of hepatitis A was identified through voluntary molecular surveillance in the Netherlands. It involved two highly similar strains of hepatitis A virus (HAV) genotype IB that were closely related to strains found in travellers from a specific region in the Middle East. Both strains were identical to strains found in earlier outbreaks in the Netherlands during the first half of $2010[1,2]$. One of the sequences was closely related to one found during an outbreak in Australia in 2009 [3] and the other sequence to one that caused an outbreak in France in 2010 [4,5].These earlier outbreaks had all been epidemiologically linked to the consumption of semi-dried tomatoes. The Dutch cluster coincided with an urgent request from England in the European reporting system EPIS, concerning the same molecular sequence [6].

The overall number of the reported hepatitis $A$ cases was not higher than expected for that time of year. However, since the cases were not epidemiologically linked, and molecular sequencing found that the strains were rare and identical to previous outbreaks, an outbreak investigation was initiated. Close collaboration was established with the Dutch Food Safety Authority
(NVWA) and the Health Protection Agency in England through telephone conferences to share updates and data [6]. With this article, we aim to alert other countries to be aware that this hepatitis strain and the contaminated product may be circulating, and to initiate source tracing if they detect the strain.

\section{HAV surveillance in the Netherlands}

HAV infections are notifiable in the Netherlands and reported to the National Institute for Public Health and the Environment (RIVM) according to standardised criteria [7]. Sera from confirmed hepatitis A cases, if available, are sent to the RIVM by the laboratories. Viral RNA is extracted from IgM positive sera, and the $460 \mathrm{nt} \mathrm{VP}_{1} / 2 \mathrm{~A}$ region is sequenced and compared to sequences recorded in the Dutch [8] and an international HAV sequence database of the Food-Borne Viruses in Europe (FBVE) network [9].

From July to October 2009 and July to October 2010, respectively, 66 and 111 hepatitis $A$ cases were reported in the Dutch mandatory notification, of which 14 and 53 acquired their infection in the Netherlands. Over the same period in 2011, there were 68 overall hepatitis A cases of which 24 acquired their infection in the Netherlands.

\section{Outbreak investigation}

Confirmed cases were defined as laboratory-confirmed HAV cases who had no travel history to endemic countries, no male-to-male sexual contacts and was therefore considered as exposed to an unknown source in the Netherlands, who had a date of symptom onset from July to November 2011 and who was infected with the specific genotype IB strain identical to strains that 
caused previous outbreaks in Europe and Australia in 2009-10 [1-5], i.e. Hu/Netherlands/RIVM-006/2010, closely related to Genbank accession number FJ687511, or $\mathrm{Hu} /$ Netherlands/RIVM-077/2010, closely related to strain FR-2010-LOUR, (GenBank Acc. No. GU646039). Cases related to primary cases and with onset of illness two weeks or more after the primary case were considered secondary cases. A probable case followed the same criteria but without laboratory confirmation.

Cases were contacted by the Dutch municipal health services and were requested to complete a questionnaire. The questionnaire included personal information like date of birth, sex, place of residence, vaccination status, symptoms, date of symptom onset and food history in the period two to six weeks before symptom onset. As recommended by the NVWA, questions on food consumption included a wide range of food products imported from the Middle East because of the similarity of the outbreak strain to strains in travellers from Middle East. The NVWA performed source tracing on the basis of questionnaire information, and tested the indicated food product for presence of hepatitis $A$ RNA using methods described elsewhere [10].

The FBVE network [11] was alerted and asked to share sequences in the international database.

\section{Description of the cases}

By November, seven confirmed cases and one probable case had been identified in the Netherlands: two women and six men aged between 20 and 75 years. The date of onset of symptoms was between 29 July and 24 October 2011 (Figure). One of the seven confirmed cases was probably a secondary case (date of onset on 24 October 2011) because she was epidemiologically linked to the probable case with date of onset on 20 September 2011. Unfortunately, the serum sample of this probable case did not yield a PCR product, which may be explained by the fact that it was obtained on 4 November, i.e. 45 days after onset of disease. In a study by Tjon et al. sera were HAV RNA-positive for a median period of 42 days after onset of illness [12].

The HAV strain Hu/Netherlands/RIVM-006/2010 was found in the first four confirmed cases and the $\mathrm{Hu} /$ Netherlands/RIVM-077/2010 strain was found in the following three confirmed cases (Figure).

Six of seven confirmed cases completed the questionnaire, including the probable secondary confirmed case. All of them indicated the consumption of ready-to-eat (RTE) packaged salads obtained from two supermarket chains, however they did not, or not fully, specify the type of salad they had consumed. On the basis of initial reports from the Dutch municipal health services, $75 \%$ of the mentioned RTE packaged salads contained semi-dried tomatoes or dried tomatoes (tomato granulates). Nevertheless, only three of six cases specifically indicated to have consumed dried or semi-dried tomatoes. In November 2011, the NVWA systematically sampled stocks of semi-dried and dried tomatoes to be used as ingredients in RTE salads and present in store houses of the suppliers of the two supermarket chains involved. A total of 114 food samples were tested, but in none of the samples HAV RNA could be detected. It remained unclear whether the tested batches were the same as those consumed by the patients. The NVWA worked in close collaboration with the Food Standards Agency (FSA) in England, but a common link in the supply chain to the Dutch and English supermarket chains could not be identified.

The international alert and the sharing of sequences in the international database resulted in a case reported from Australia who locally acquired an infection with an HAV strain identical to Hu/Netherlands/RIVM-006/2010 in a $311 \mathrm{nt}$ sequence in the VP1/2A genomic region. For this case source tracing is currently ongoing.

\section{Conclusion and recommendations}

Seven confirmed hepatitis A cases and one probable case were identified in the Netherlands with HAV genotype IB strains identical or closely related to the ones found recently in England and Australia and in previous food-borne outbreaks in the Netherlands, Australia and France. All cases that completed the questionnaire indicated consumption of RTE salads, including those containing semi-dried tomatoes, during their incubation period. However, only three cases specifically indicated to have consumed semi-dried tomatoes. Because of the low number of cases, the long and variable incubation period, the long time between dates of onset of the first and of the last cases, and the complexity of the traceback, no common source could be identified. These were also the reasons for not including controls in our study. This might be considered a limitation,

\section{FIGURE}

Confirmed and probable cases of hepatitis A, indicated by two closely related molecular sequences $\left(10-006^{\mathrm{a}}\right.$ and $\left.10-077^{\mathrm{b}}\right)$, notified in the Netherlands from March to December $2011(n=8)$

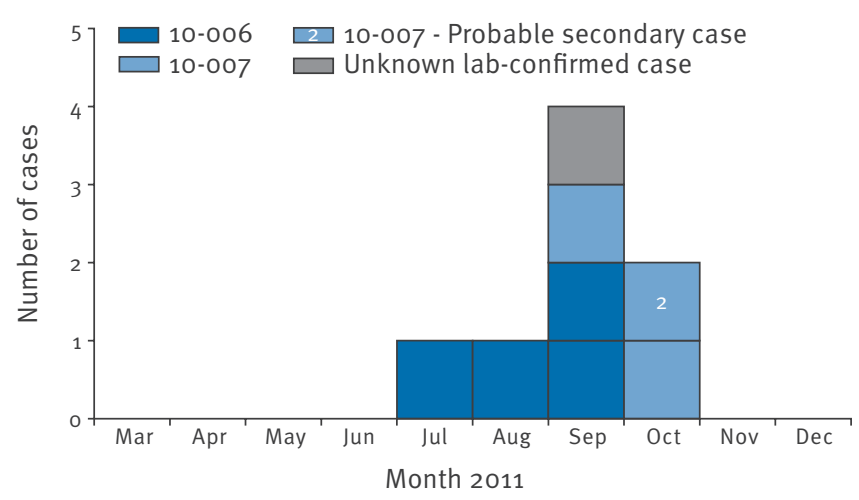

10-006: Hu/Netherlands/RIVM-006/2010; strain detected in Netherlands 2010, closely related to strain detected in Australia 2009.

b 10-077: Hu/Netherlands/RIVM-077/2010; strain detected in Netherlands 2010, closely related to strain detected in France $2009 / 10$. 
since we were not able to find an association to a single food product.

Until the time of publication of this report, no new cases have been reported. Nevertheless, we cannot exclude contaminated food items like RTE salads or semi-dried tomatoes being in circulation. Given the difficulty of identifying and tracing an international common food-borne source, combining information on all infected cases is of utmost importance. We are therefore interested in all cases infected with the HAV IB strains described here. The HAV database of the FBVE network can be used to compare sequences. Information on linked cases and requests for access to the database or assistance in source tracing activities can be addressed by email to fbve@rivm.nl.

\section{Acknowledgments}

We would like to thank the people working at the municipal health services for their extra efforts and help in source tracing, and the laboratories for sending in the sera to RIVM for molecular typing. We are grateful to the people working at the NVWA for their close collaboration in this investigation and their willingness to share their data internationally. Especially, we like to thank Jan van Kooij for his involvement in the initial phase of the outbreak, Gabriel Mainer Albiac for identifying food products derived from the specific geographical region, Geke Hägele and Nathalie te Loeke for the viral analyses of the many food samples. We like to thank the people from the HPA and FSA in England for their close collaboration throughout the outbreak investigation, especially Koye Balogun, Carlos Carvalho, Lucy Thomas, Siew Lin Ngui, and Joanne Aish. We would like to thank Michael Lyon for sharing the Australian sequence data in the international hepatitis A database.

\section{References}

1. Petrignani $M$, Verhoef $L$, van Hunen $R$, Swaan $C$, van Steenbergen J, Boxman I, et al. A possible foodborne outbreak of hepatitis A in the Netherlands, January-February 2010. Euro Surveill. 2010;15(11):pii=19512. Available from: http://www. eurosurveillance.org/ViewArticle.aspx?Articleld=19512

2. Petrignani $M$, Harms $M$, Verhoef $L$, van Hunen $R$, Swaan $C$, van Steenbergen J, et al. Update: a food-borne outbreak of hepatitis $A$ in the Netherlands related to semi-dried tomatoes in oil, January-February 2010. Euro Surveill. 2010;15(20):pii=19572. Available from: http://www. eurosurveillance.org/ViewArticle.aspx?Articleld=19572

3. Donnan EJ, Fielding JE, Gregory JE, Lalor K, Rowe S, Goldsmith $P$, et al. A multistate outbreak of hepatitis A associated with semidried tomatoes in Australia, 2009. Clin Infect Dis. 2012 Jan 11. [Epub ahead of print]

4. Couturier E, Grout L, Roque-Afonso A, Gallot C, Pouey I, Letort $M$, et al. Épidémie d'hépatite $A$ liée à la consommation de tomates semi-séchées, France, 2009-2010. [Hepatitis A outbreak linked to the consumption of semi-dried tomatoes, France, 2009-2010]. Bull Epidémiol Hebd. 2011;13-14:165-8.

5. Gallot C, Grout L, Roque-Afonso AM, Couturier E, CarrilloSantisteve P, Pouey J, et al. Hepatitis A associated with semidried tomatoes, France, 2010. Emerg Infect Dis.17(3):566-7.

6. Carvalho C, Thomas HL, Balogun K, Tedder R, Pebody R, Ramsay M, et al. A possible outbreak of hepatitis A associated with semi-dried tomatoes, England, July-November 2011. Euro Surveill. 2012;17(6):pii=20083. Available from: http://www. eurosurveillance.org/ViewArticle.aspx?Articleld $=20083$

7. Suijkerbuijk AW, Lindeboom R, van Steenbergen JE, Sonder GJ, Doorduyn Y. Effect of hepatitis A vaccination programs for migrant children on the incidence of hepatitis $A$ in The Netherlands. Eur J Public Health. 2009;19(3):240-4.
8. Van Steenbergen J, Petrignani M, Kroneman A, Koopmans M. The molecular epidemiology of hepatitis A in The Netherlands; the usefulness of typing isolated viral strains. Ned Tijdschr Geneeskd. 2008;152(7):408. Dutch.

9. Duizer E, Kroneman A, Siebenga J, Verhoef L, Vennema H, Koopmans $M$, et al. Typing database for noroviruses. Euro Surveill. 2008;13(19):pii=18867. Available from: http://www. eurosurveillance.org/ViewArticle.aspx?Articleld =18867

10. Boxman IL, Te Loeke NA, Klunder K, Hagele G, Jansen CC. Surveillance study of hepatitis A virus RNA on fig and date samples. Appl Environ Microbiol. 2012;78(3):878-9.

11. Koopmans M, Vennema $H$, Heersma $H$, van Strien $E$, van Duynhoven Y, Brown D, et al. Early identification of commonsource foodborne virus outbreaks in Europe. Emerg Infect Dis. 2003;9(9):1136-42.

12. Tjon GM, Coutinho RA, van den Hoek A, Esman S, Wijkmans C), Hoebe CJ, et al. High and persistent excretion of hepatitis A virus in immunocompetent patients. J Med Virol. 2006;78(11):1398-405. 